\title{
Automatic Segmentation Techniques of the Coronary Artery Using CT Images in Acute Coronary Syndromes
}

\author{
Sándor Miklós Szilágyi ${ }^{1}$, Monica Marton Popovici², László Szilágyi ${ }^{3}$ \\ ${ }^{1}$ Department of Informatics, Petru Maior University, Tîrgu Mureș, Romania \\ ${ }^{2}$ Swedish Medical Center, Department of Anesthesiology and Critical Care, Seattle, USA \\ ${ }^{3}$ Department of Electrical Engineering, Sapientia University, Tîrgu Mureș, Romania
}

\begin{abstract}
Coronary artery disease represents one of the leading reasons of death worldwide, and acute coronary syndromes are their most devastating consequences. It is extremely important to identify the patients at risk for developing an acute myocardial infarction, and this goal can be achieved using noninvasive imaging techniques. Coronary computed tomography angiography (CCTA) is currently one of the most reliable methods used for assessing the coronary arteries; however, its use in emergency settings is sometimes limited due to time constraints. This paper presents the main characteristics of plaque vulnerability, the role of CCTA in the assessment of vulnerable plaques, and automatic segmentation techniques of the coronary artery tree based on CT angiography images. A detailed inventory of existing methods is given, representing the state-of-the-art of computational methods applied in vascular system segmentation, focusing on the current applications in acute coronary syndromes.
\end{abstract}

Keywords: image segmentation, computed tomography, pattern recognition coronary artery disease, emergency cases

\section{ARTICLE HISTORY}

Received: 13 January, 2017

Accepted: 19 February, 2017

CORRESPONDENCE

Sándor Miklós Szilágyi

Str. N. Iorga nr. 1

540088 Tîrgu Mureș, Romania

Tel: +40 265262275

E-mail: sandoor.szilagyi@science.upm.ro

\section{ACUTE CORONARY SYNDROMES}

Coronary artery disease (CAD) is one of the leading causes of death worldwide, responsible for the death of millions every year. ${ }^{1}$ World Health Organization (WHO) statistics show that in 2012, 31\% of all deaths were caused by cardiovascular disease, from which 7.4 million were due to coronary heart disease. ${ }^{2}$ Acute coronary syndromes (ACS) are among the most severe complications of atherosclerosis, and the majority, although not all, take place due to atheromatous plaque rupture and subsequent thrombosis. $^{3}$

\section{VULNERABLE ATHEROMATOUS PLAQUES}

The genesis of the atheroma is triggered by the appearance of a discontinuity in the endothelial layer, followed by an array of complex mechanical, biochemical, and biological mechanisms that will eventually lead to plaque formation..$^{-6}$ The formed atherosclerotic plaque will undergo several pathophysiological changes, including the excessive accumulation of oxidized LDL-cholesterol, enhanced local inflammation, smooth muscle cell proliferation, and extracellular matrix degradation, which will eventually lead to its progression and destabilization. ${ }^{7}$ 
In an attempt to define the complications related to atherosclerotic plaques and to find the pathophysiological mechanism of acute coronary syndromes, the concept of "vulnerable plaque" was developed. ${ }^{8}$ The definition of the vulnerable coronary plaque comprises an increased propensity towards rupture, erosion, and thrombosis.,, 10

A vulnerable plaque is described as having a thin fibrous cap and a large necrotic lipid core that initially causes an eccentric vascular remodeling (positive remodeling) followed by luminal stenosis and impaired distal blood flow. ${ }^{11-13}$ Other features of unstable coronary lesions include an increased local inflammation, ${ }^{14}$ extracellular matrix degradation, ${ }^{15}$ neo-vessel formation within the plaque with subsequent hemorrhage, ${ }^{16,17}$ as well as calcium formation in the form of spotty calcifications. ${ }^{18}$

Even though the most common fate of an unstable plaque is to rupture, a significant percentage of acute coronary syndromes were shown to be caused by coronary plaque erosion. ${ }^{19}$ Lesions that suffer erosions seem to not show the established characteristics of a vulnerable plaque, usually presenting a thick cap, decreased necrotic cores and lower inflammation degree. ${ }^{20}$ Thus came the idea that a vulnerable plaque is not as much prone to rupture, but more prone to causing an acute event. ${ }^{21}$

\section{SHEAR STRESS AND VULNERABLE PLAQUES}

The complex pathophysiological mechanism of atherosclerosis includes, besides progressive endothelial injury, local inflammation, and vascular remodeling, also hemodynamic alterations. ${ }^{22}$ It was shown that there is an increased occurrence of coronary plaques in vascular regions with high shear stress, such as bifurcations or near vascular curvatures. ${ }^{23}$ Also, the protrusion of the atheroma in the vessel lumen causes a shift from a normal, laminar flow, with evenly distributed transverse and shear stress, to a turbulent flow. ${ }^{24}$ Coronary shear stress (CSS) has been shown to influence the progression of coronary plaques by causing structural and functional changes in the endothelium, enzymatic changes, release of bioactive markers, and gene transcription. ${ }^{25,26}$ Low shear stress (LSS) leads to misalignment of the endothelial cells, increased permeability to circulating lipid molecules and inflammatory cytokines, as well as high expression of adhesion molecules, growth factors, and high reactive oxygen species. ${ }^{22,27-29}$ In the context of increased systemic cardiovascular risk factors, the dysfunctional endothelium and increased inflammatory status augment the process of plaque growth and cause additional alterations of the endothelial shear stress. ${ }^{30}$ High shear stress exposure presents a protective effect on healthy ves- sels, but if a stenotic lesion is present, it indorses plaque vulnerabilization..$^{31}$ High shear stress contributes to plaque destabilization by increased nitric oxide expression and extracellular matrix degradation by stimulating the expression of matrix metalloproteases, increased production of proteolytic enzymes, and apoptosis. ${ }^{32-34}$ Furthermore, an increased CSS can stimulate plaque denudation and erosion, which, if associated with an enhanced blood thrombogenicity, lead to acute vessel occlusion and the occurrence of an ACS. ${ }^{21,35}$ Shear stress distribution across coronary stenotic lesions appears to be low in the distal region of the plaque, whilst a high stress is mainly present in the proximal part. ${ }^{36,37}$ In order to maintain the physiological shear stress, vascular remodeling occurs as an adaptive process, ${ }^{38}$ thus a high CSS stimulates an outward remodeling, while a low CSS exposure will lead to an inward remodeling with vessel narrowing. ${ }^{39}$

\section{METHODS FOR THE ASSESSMENT OF VULNERABLE PLAQUE CHARACTERISTICS}

There are several established methods for the assessment of biomarkers characteristic for plaque instability, acquired with both invasive and noninvasive techniques..$^{40}$ The invasive methods include intravascular ultrasound (IVUS) with its different variations (virtual histology IVUS, iMAP IVUS, and integrated backscatter IVUS), which can assess with high accuracy the total plaque burden, necrotic core, neo-vessel formation, calcifications, as well as the vessel remodeling percentage. ${ }^{41-43}$ Optical coherence tomography (OCT), which uses near-infrared light for image acquisition, allows evaluation of the fibrous cap, collagen amount, neoangiogenesis, plaque rupture and thrombus formation; its variant, micro-OCT, is able to offer a histological level of accuracy in the process of plaque component visualization. ${ }^{21,44,45}$ Other invasive methods for evaluating unstable coronary plaques include invasive coronary thermography (which measures plaque temperature), ${ }^{46}$ near-infrared spectroscopy (NIRS - better visualization of necrotic cores), ${ }^{47}$ and also combinations of the above-mentioned methods..$^{48,49}$ Coronary computed tomography angiography (CCTA) has emerged as the most used technique for noninvasive plaque evaluation, being able to identify several CT biomarkers for plaque instability. ${ }^{40}$ The advantages of this method are that it is noninvasive, it allows the visualization of the complete coronary tree, and it also holds the ability to analyze both the vascular lumen and the wall. ${ }^{50}$ Moreover, recent developments have led to an increase in image quality and resolution, by using multiple slice scans with ECG-gat- 
ed protocols that allow imaging acquisition in a single heartbeat, during diastole, thus eliminating motion artifacts. ${ }^{51,52}$ CCTA displays an increased rule-out capacity for lesion identification and quantification, and studies have shown that its detection accuracy is comparable to invasive methods (IVUS and OCT), even if it does not hold the ability for fibrous cap identification. ${ }^{21,53,54}$ Major advantages of the latter are: 3D data collection and visualization, as well as information on arterial calcification and vascular distortion. ${ }^{55}$ The markers for plaque vulnerability that are identified by CCTA are the presence and size of the necrotic core (which appears as a hypodense area within the plaque), ${ }^{56,57}$ low attenuation plaques, ${ }^{58}$ positive remodeling (and calculation of the remodeling index), ${ }^{59}$ the presence of the napkin-ring sign, ${ }^{60}$ and microcalcification within the plaque (referred to as spotty calcifications). ${ }^{61,62}$ CCTA is also able to evaluate the overall degree of calcification of the coronary tree by using the coronary artery calcium score, which has been shown to have a high predictive capacity for major adverse cardiovascular events, being combined with traditional cardiovascular risk factors (c-statistic of 0.93). ${ }^{63}$

Other applications of CCTA include the noninvasive assessment of coronary blood flow and the function significance of coronary lesions, with the use of CT-based fractional flow reserve (CT-FFR), ${ }^{64,65}$ as well as the transluminal attenuation gradient through a coronary stenosis. ${ }^{66}$ Nevertheless, CCTA has a great potential of being integrated into computational simulation models for coronary flow and fluid dynamics, which will allow the analysis of plaque conduct in physiological and pathological circumstances. ${ }^{21}$ Computational models are the sole methods that are currently able to integrate both the external (hemodynamic) and internal (characteristics of plaque) markers for instability in order to achieve a global understanding of the conditions that lead to plaque erosion and rupture with the subsequent occurrence of an acute coronary syndrome. ${ }^{21,67,68}$ One of the most important drawbacks of computational simulation models is the increased time needed for image reconstruction, but with recent developments, the time has been reduced from weeks ${ }^{69}$ to less than two hours, ${ }^{70}$ which will make it possible for computational plaque analysis to be performed as a part of a living vessel..$^{21}$

Accurately identifying coronary plaques is challenging, especially when using noninvasive methods such as CCTA. The problems encountered in the CT analysis of coronary plaques include the presence of non-calcified lesions, small sized vessels, as well as motion artifacts that can be diminished by using ECG-gated CT protocols, multiplanar image acquisition and vessel segmentation, and vascular tree reconstruction techniques. ${ }^{71,72}$

\section{CORONARY TREE SEGMENTATION}

The segmentation of vascular trees is a widely researched topic. The literature includes several studies that follow the data-driven approach, namely they treat the notion of the vascular tree in a general way, as a set of interconnected tubular structures, with possible bifurcations and stenoses, but without using any anatomical information. These studies usually concentrate on image quality enhancement for vessel recognition, ${ }^{73}$ accurate detection of bifurcations and branches, ${ }^{74-77}$ extraction of the most probable centerline, ${ }^{78,79}$ vessel diameter estimation, ${ }^{79,80}$ and the identification of odd structures. ${ }^{81,82}$ Although they are very important in the development of useful medical data processing techniques, these general studies do not take into consideration any anatomical information of a chosen vessel tree.

On the other hand, the literature also includes studies on arterial tree segmentation procedures designed for and tested on specific arterial networks. The major part of such studies focuses on the coronary artery tree (CAT), 83,84 but there are several works developed for the pulmonary arteries, ${ }^{85-88}$ cerebral arteries, ${ }^{89}$ the carotid artery, ${ }^{90}$ and vessels of the retina. ${ }^{91,92}$

\section{SEGMENTATION METHODS FOR CORONARY ARTERIES IN ACUTE CORONARY SYNDROMES}

\section{DATA-DRIVEN SEGMENTATION METHODS}

Cimen et al.93,94 proposed a method to reconstruct 3D views of the CAT from $2 \mathrm{D} \mathrm{X}$-ray images based on a probabilistic mixture model and maximum likelihood estimation. Hu et al. ${ }^{95}$ proposed a two-step solution for the same problem: in a first stage they extracted artery tree boundaries via minimal path segmentation, then applied maximum a posteriori (MAP) reconstruction using Lo-norm and L1-norm priors. Fallavollita and Cheriet $^{96}$ provided a 3D coronary artery reconstruction technique from reduced number of 2D X-ray fluoroscopy images that follows the non-rigid movement of arteries, significantly decreasing the reconstruction error.

Gülsün et al. ${ }^{97}$ employed computed flow fields to eliminate shortcuts in automatically detected blood vessel centerlines, and Kitamura et al..$^{98}$ used a Markov Random Field framework and AdaBoost classifier for vascular structure segmentation, assisted by topological constraints in order 
to avoid inconsistency in the vascular network. Dufour et al. ${ }^{99}$ combined the Hessian matrix approach and the graylevel hit-or-miss transform to obtain vessel candidate pixels in CTA data, which were later classified using decision trees. Krissian et al. ${ }^{100}$ established a geodesic level set framework to semi-automatically detect the aorta with its main bifurcations and branches, extract the centerline of each branch, and identify the presence of aortic dissection. Zhou et al..$^{83}$ introduced the notion of multiscale coronary response, a robust method designed to find coronary arteries via combining 3D multiscale filtering, analysis of the eigenvalues of the Hessian matrices, and expectation maximization (EM) estimation techniques. They also employed a 3D dynamic balloon tracking method to extract complete artery trees. Shang et al. ${ }^{101}$ defined a vector field based on the eigenanalysis of the Hessian matrix and used it to assist a 3D active contour model in the detection of vascular structures.

\section{MODEL-DRIVEN SEGMENTATION METHODS}

The most part of recently developed CAT segmentation methods follows the model-based or the model-driven approach, through involving anatomical models or atlases to improve the segmentation accuracy. Model-based methods start with extracting relevant information from the recorded image data, but in a later processing phase they match the extracted information with predefined atlases or models.

Shin et al. ${ }^{102}$ employed a manually annotated 2D fluoroscopic X-ray image as reference and proposed a technique to extract coronary vessels from further images via vessel correspondence optimization. Liu et al. ${ }^{103,104}$ proposed a model-guided centerline extraction method based on ostia detection via directional minimal paths and validated it on the three main branches of the CAT in CTA image data. Sun et al. ${ }^{105}$ deployed a previously recorded 3D vessel model of the same patient to track the position of various branches within 2D X-ray angiograms, using exploratory shortest paths within the graph model of the vessels. Medrano-Garcia et al. ${ }^{106}$ built a coronary artery atlas using 122 CTA records of zero calcium score, providing a comprehensive and accurate assessment of the anatomy, including 3D size, geometry, and shape descriptors.

In model-driven methods the identification of vessels and centerlines relies on a priori defined cardiovascular models. For example, the method proposed by Zheng et al. ${ }^{107}$ automatically segments the heart chambers and then uses an anatomical model to automatically track various branches of the CAT. The model helps the centerline tracing procedure to avoid early termination at severe occlusions and to generate anatomically consistent centerlines.

\section{THE DESIGN OF THE SEGMENTATION METHOD}

The main steps of the proposed solution include preprocessing, seed extraction for region growing, data-driven segmentation via robust fuzzy region growing, centerline extraction, model-based validation and vessel identification, and post-processing. ${ }^{108-112}$

\section{THE USE OF CT IN EMERGENCY SETTINGS AND FOR ACUTE CORONARY SYNDROMES}

The use of CCTA has been shown to be feasible and useful for patients who present in the emergency department for acute chest pain, but have equivocal laboratory and electrocardiographic (ECG) modifications. The Rule Out Myocardial Infarction/Ischemia Using Computer Assisted Tomography (ROMICAT-I) trial included 368 patients with acute chest pain, normal initial troponin values, and no signs of myocardial ischemia on the initial ECG.113 The results showed that emergency CCTA had a high negative predictive value (100\% in the absence of $\mathrm{CAD}, 98 \%$ in the presence of significant coronary lesions) in ruling out an acute coronary syndrome. ${ }^{113}$

Another trial on the use of CCTA in the emergency department (ED), which included 1,000 patients with acute chest pain, showed that in comparison to a traditional diagnostic procedure (invasive coronary angiography), the hospitalization index was decreased by $7.6 \mathrm{~h}$ (period of stay in the emergency department), and a significantly larger number of patients had been discharged straight from the ED ( $47 \%$ for CCTA vs. $12 \%$ for the invasive approach). ${ }^{114}$

As it allows rule-out of acute pulmonary embolism, aortic dissection, and acute coronary syndromes, depiction of the complete coronary anatomy, illustration of the coronary vessel lumen, identification of vulnerable plaque features, as well as the coronary artery calcium score, CCTA is a valuable method for emergency triage and patient management, for the decision-making process and prognosis assessment of patients with coronary artery disease, all in a noninvasive stand-alone procedure. ${ }^{55,115-117}$ The noninvasive visualization of plaque characteristics and severity of the coronary artery disease in patients with non-ST elevation acute coronary syndromes at baseline, was shown to predict recurrent adverse events. ${ }^{118}$ 


\section{CONCLUSIONS}

Computational methods can be easily applied in the vascular system for coronary artery tree segmentation using CTA image volumes. This interdisciplinary approach can provide a solid background for a complex assessment of the coronary tree, especially in settings when estimation of the degree of plaque vulnerability can be crucial for the future evolution of the patients.

\section{CONFLICT OF INTEREST}

Nothing to declare.

\section{ACKNOWLEDGEMENT}

This work was supported by the UEFISCDI PN-III-P2-2.1BG-2016-0343 national research project.

\section{REFERENCES}

1. Roger VL, Go AS, Lloyd-Jones DM, et al. Heart disease and stroke statistics - 2012 update: a report from the American Heart Association. Circulation. 2012;125:e2-e220. doi: 10.1161/ CIR.ob013e31823ac046.

2. World Health Organization, Cardiovascular disease (CVDs), 2016. Available from: http://www.who.int/mediacentre/ factsheets/fs317/en/\#

3. Choy SY, Mintz GS. What have we learned about plaque rupture in acute coronary syndromes? Curr Cardiol Rep. 2010;12:338-343. doi: 10.1007/s11886-010-0113-X.

4. Tominaga J, Fukunaga Y, Abelardo E, Nagafuchi A. Defining the function of beta-catenin tyrosine phosphorylation in cadherin-mediated cell-cell adhesion. Genes Cells. 2008;13:67-77. doi: 10.1111/j.1365-2443.2007.01149.x.

5. Cheruvu PK, Finn AV, Gardner C, et al. Frequency and distribution of thin-cap fibroatheroma and ruptured plaques in human coronary arteries: a pathologic study. J Am Coll Cardiol. 2007;50:940-949. doi: 10.1016/j.jacc.2007.04.086.

6. Saybolt MD, Lilly SM, Patel D, et al. The vulnerable artery: early and rapid deposition of lipid in coronary arteries is associated with subsequent development of thin-cap fibroatheromas. EuroIntervention. 2016;11:e1612-e1618. doi: 10.4244/EIJV11I14A312.

7. Stary HC, Chandler AB, Glagov S, et al. A definition of initial, fatty streak, and intermediate lesions of atherosclerosis. A report from the Committee on Vascular Lesions of the Council on Arteriosclerosis, American Heart Association. Circulation 1994;89:2462-2478.

8. Finn AV, Nakano M, Narula J, Kolodgie FD, Virmani R. Concept of vulnerable/unstable plaque. Arterioscler Thromb Vasc Biol. 2010;30:1282-1292. doi: 10.1161/ATVBAHA.108.179739.

9. Bourantas CV, Garcia-Garcia HM, Farooq V, et al. Clinical and angiographic characteristics of patients likely to have vulnerable plaques: analysis from the PROSPECT study. JACC Cardiovasc Imaging. 2013;6:1263-1272. doi: 10.1016/j. jcmg.2013.04.015.
10. Bentzon JF, Otsuka F, Virmani R, Falk E. Mechanisms of plaque formation and rupture. Circ Res. 2014;114:1852-1866. doi: 10.1161/CIRCRESAHA.114.30272.

11. Schaar JA, Muller JE, Falk E, et al. Terminology for highrisk and vulnerable coronary artery plaques. Eur Heart J. 2004;25:1077-1082. doi:10.1016/j.ehj.2004.01.002.

12. Varnava AM, Mills PG, Davies MJ. Relationship between coronary artery remodeling and plaque vulnerability. Circulation. 2002;105:939-943.

13. Ota H, Magalhaes MA, Torguson $\mathrm{R}$, et al. The influence of lipid-containing plaque composition assessed by nearinfrared spectroscopy on coronary lesion remodelling. Eur Heart J Cardiovasc Imaging. 2016;17:821-831. doi: 10.1093/ ehjci/jev221.

14. Hansson GK, Hermansson A. The immune system in atherosclerosis. Nat Immunol. 2011; 12:204-212. doi: 10.1038/ ni.2001.

15. Newby A. Metalloproteinases and Vulnerable Atherosclerotic Plaques. Trends Cardiovasc Med. 2010;17:253-258. doi: 10.1016/j.tcm.2007.09.001.

16. Taruya A, Tanaka A, Nishiguchi $\mathrm{T}$, et al. Vasa vasorum restructuring in human atherosclerotic plaque vulnerability: a clinical optical coherence tomography study. J Am Coll Cardiol. 2015;65:2469-2477. doi: 10.1016/j.jacc.2015.04.020.

17. Yokoya K, Takatsu H, Suzuki T, et al. Process of progression of coronary artery lesions from mild or moderate stenosis to moderate or severe stenosis: a study based on four serial coronary arteriograms per year. Circulation. 1999;100:903909.

18. Sakaguchi M, Hasegawa T, Ehara S, et al. New insights into spotty calcification and plaque rupture in acute coronary syndrome: an optical coherence tomography study. Heart Vessels. 2016;31:1915-1922. Doi: 10.1007/s00380-0160820-3.

19. Jia H, Dai J, Hou J, et al. Effective anti-thrombotic therapy without stenting: intravascular optical coherence tomography-based management in plaque erosion (the EROSION study). Eur Heart J. 2016;38:792-800. doi: 10.1093/ eurheartj/ ehw381.

20. Bentzon JF, Otsuka F, Virmani R, Falk E. Mechanisms of plaque formation and rupture. Circ Res. 2014;114:1852-1866. doi: 10.1161/CIRCRESAHA.114.302721.

21. Stefanidis C, Antoniou C, Tsiachris D, Pietri P. Coronary Atherosclerotic Vulnerable Plaque: Current Perspectives. J Am Heart Assoc. 2017;6:e005543. doi: 10.1161/JAHA.117.005543.

22. Thondapu V, Bourantas C, Foin N, et al. Biomechanical stress in coronary atherosclerosis: emerging insights from computational modelling. Eur Heart J. 2017;38:81-92. doi:10.1093/eurheartj/ehv689.

23. McDaniel M, Galbraith E, Jeroudi A, et al. Localization of culprit lesions in coronary arteries of patients with STsegment elevation myocardial infarctions: relation to bifurcations and curvatures. Am Heart J. 2011;161:508-515. doi: 10.1016/j.ahj.2010.11.005.

24. Chiu J, Chien S. Effects of Disturbed Flow on Vascular Endothelium: Pathophysiological Basis and Clinical Perspectives. Physiol Rev. 2011;91:327-387. doi: 10.1152/ physrev.00047.2009.

25. Koskinas K, Chatzizisis Y, Baker A, Edelman E, Stone P, Feldman L. The role of low endothelial shear stress in the conversion of atherosclerotic lesions from stable to unstable plaque. Curr Opin Cardiol. 2009;24:580-590. doi: 10.1097/ HCO.ob013e328331630b. 
26. Cunningham KS, Gotlieb AI. The role of shear stress in the pathogenesis of atherosclerosis. Lab Invest. 2005;85:9-23. doi: 10.1038/labinvest.3700215.

27. Chen Z, Peng C, Cui X, LiY S, Chien S, Shyy J. Shear stress, SIRT 1, and vascular homeostasis. Proc Natl Acad Sci USA. 2010;107:10268-10273. doi: 10.1073/pnas.1003833107.

28. Gambillara V, Montorzi G, Haziza-Pigeon C, Stergiopulos $\mathrm{N}$, Silacci P. Arterial wall response to ex vivo exposure to oscillatory shear stress. J Vasc Res. 2005;42:535-544. doi: 10.1159/000088343.

29. Sucosky P, Balachandran K, Elhammali A, Jo H, Yoganathan AP. Altered shear stress stimulates upregulation of endothelial VCAM-1 and ICAM-1 in a BMP-4and TGF-beta1-dependent pathway. Arterioscler Thromb Vasc Biol. 2009;29:254-260. doi: 10.1161/ATVBAHA.108.176347.

30. Gimbrone MA, Topper JN, Nagel T, Anderson KR, GarciaCardena G. Endothelial dysfunction, hemodynamic forces, and atherogenesis. Ann NY Acad Sci. 2000;902:230-240.

31. Samady H, Eshtehardi P, McDaniel MC, et al. Coronary artery wall shear stress is associated with progression and transformation of atherosclerotic plaque and arterial remodeling in patients with coronary artery disease. Circulation. 2011;124:779-788. doi: 10.1161/ CIRCULATIONAHA.111.021824.

32. Dancu MB, Berardi DE, Vanden Heuvel JP, Tarbell JM. Asynchronous shear stress and circumferential strain reduces endothelial NO synthase and cyclooxygenase- 2 but induces endothelin-1 gene expression in endothelial cells. Arterioscler Thromb Vasc Biol. 2004;24:2088-2094. doi: 10.1161/01.ATV.0000143855.85343.0e.

33. Gijsen FJH, Mastik F, Schaar JA, et al. High shear stress induces a strain increase in human coronary plaques over a 6-month period. EuroIntervention. 2011;7:121-127. doi: 10.4244/EIJV7I1A20.

34. Wang Y, Qiu J, Luo S, et al. High shear stress induces atherosclerotic vulnerable plaque formation through angiogenesis. Regen Biomater. 2016;3:257-267. doi: 10.1093/ $\mathrm{rb} / \mathrm{rbw} 021$.

35. Kramer M, Rittersma S, de Winter R, et al. Relationship of thrombus healing to underlying plaque morphology in sudden coronary death. J Am Coll Cardiol. 2010;55:122-132. doi: 10.1016/j.jacc.2009.09.007.

36. Slager CJ, Wentzel JJ, Gijsen FJ, et al. The role of shear stress in the generation of rupture-prone vulnerable plaques. Nat Clin Pract Cardiovasc Med. 2005;2:401-407.

37. Wentzel JJ, Chatzizisis YS, Gijsen FJ, et al. Endothelial shear stress in the evolution of coronary atherosclerotic plaque and vascular remodelling: current understanding and remaining questions. Cardiovasc Res. 2012;96:234-243. doi: 10.1093/cvr/ cvs217.

38. Chung WB, Hamburg NM, HolbrookM, et al. The brachial artery remodels to maintain local shear stress despite the presence of cardiovascular risk factors. Arterioscler Thromb Vasc Biol. 2009;29:606-612. doi: 10.1161/ATVBAHA.108.181495.

39. Freidja ML, Toutain B, Caillon A, et al. Heme oxygenase 1 is differentially involved in blood flow-dependent arterial remodeling: role of inflammation, oxidative stress, and nitric oxide. Hypertension. 2011;58:225-231. doi: 10.1161/ HYPERTENSIONAHA.111.170266.

40. Benedek T, Mester A, Benedek A, Rat N, Opincariu D, Chițu M. Assessment of Coronary Plaque Vulnerability in Acute
Coronary Syndromes using Optical Coherence Tomography or Intravascular Ultrasound. A systematic Review. Journal of Cardiovascular Emergencies. 2016;2:173-184. doi: 10.1515/ jce-2016-0028.

41. Sinclair H, Veerasamy $M$, Bourantas $C$, et al. The role of virtual histology intravascular ultrasound in the identification of coronary artery plaque vulnerability in acute coronary syndromes. Cardiol Rev. 2016;24:303-309. doi: 10.1097/ CRD.0000000000000100.

42. Calvert PA, Obaid DR, O'Sullivan M, et al. Association between IVUS findings and adverse outcomes in patients with coronary artery disease: the VIVA (VH-IVUS in Vulnerable Atherosclerosis) Study. JACC Cardiovasc Imaging. 2011;4:894901. doi: 10.1016/j.jcmg.2011.05.005.

43. Sathyanarayana S, Carlier S, Li W, Thomas L. Characterisation of atherosclerotic plaque by spectral similarity of radiofrequency intravascular ultrasound signals. EuroIntervention. 2009;5:133-139.

44. Jang IK. Optical Coherence Tomography or Intravascular Ultrasound? JACC: Cardiovascular Interventions. 2011;4:492494. doi: 10.1016/j.jcin.2011.02.004.

45. Finn AV, Chandrashekhar Y, Narula J. Vulnerable plaques: from PROSPECT to prospects... JACC Cardiovasc Imaging. 2012;5:334-336. doi: 10.1016/j.jcmg.2012.02.004.

46. Toutouzas K, Synetos A, Stefanadi E, et al. Correlation between morphologic characteristics and local temperature differences in culprit lesions of patients with symptomatic coronary artery disease. J Am Coll Cardiol. 2007;49:22642271. doi: 10.1016/j.jacc.2007.03.026.

47. Madder RD, Goldstein JA, Madden SP, et al. Detection by nearinfrared spectroscopy of large lipid core plaques at culprit sites in patients with acute ST-segment elevation myocardial infarction. JACC Cardiovasc Interv. 2013;6:838846. doi: 10.1016/j.jcin.2013.04.012.

48. Ughi GJ, Wang H, Gerbaud E, et al. Clinical characterization of coronary atherosclerosis with dual-modality OCT and nearinfrared autofluorescence imaging. JACC Cardiovasc Imaging. 2016;9:1304-1314.

49. Matter C, Stuber M, Nahrendorf M. Imaging of the unstable plaque: how far have we got? Eur Heart J. 2009;30:25662574. doi: 10.1093/eurheartj/ehp419.

50. Rodriguez-Granillo GA, Carrascosa P, Bruining N, Waksman R, Garcia-Garcia HM. Defining the non-vulnerable and vulnerable patients with computed tomography coronary angiography: evaluation of atherosclerotic plaque burden and composition. Eur Heart J Cardiovasc Imaging. 2016;17:481491. doi: 10.1093/ehjci/jew012.

51. Achenbach S, Boehmer K, Pflederer $\mathrm{T}$, et al. Influence of slice thickness and reconstruction kernel on the computed tomographic attenuation of coronary atherosclerotic plaque. J Cardiovasc Comput Tomogr. 2010;4:110-115. doi: 10.1016/j. jcct.2010.01.013.

52. Yu L, Leng S, McCollough CH. Dual-energy CT-based monochromatic imaging. AJR Am J Roentgenol. 2012;199:S9S15. doi: 10.2214/AJR.12.9121.

53. Voros S, Rinehart S, Qian Z, et al. Coronary atherosclerosis imaging by coronary CT angiography: current status, correlation with intravascular interrogation and metaanalysis. JACC Cardiovasc Imaging. 2011;4:537-548. doi: 10.1016/j.jcmg.2011.03.006.

54. Motoyama S, Ito H, Sarai M, et al. Plaque characterization by coronary computed tomography angiography and the likelihood of acute coronary events in mid-term follow- 
up. J Am Coll Cardiol. 2015;66:337-346. doi: 10.1016/j. jacc.2015.05.069.

55. Li ZX, Zhang YT, Liu GZ, Shao HY, Li WM, Tang XL. A robust coronary artery identification and centerline extraction method in angiographies. Biomed Sign Proc Contr. 2015;16:18. http://dx.doi.org/10.1016/j.bspc.2014.09.015.

56. Benedek T, Gyöngyösi M, Benedek I. Multislice computed tomographic coronary angiography for quantitative assessment of culprit lesions in acute coronary syndromes. Can J Cardiol. 2013;29:364-371. doi: 10.1016/j.cjca.2012.11.004.

57. Choi BJ, Kang DK, Tahk SJ, et al. Comparison of 64-slice multidetector computed tomography with spectral analysis of intravascular ultrasound backscatter signals for characterizations of noncalcified coronary arterial plaques. Am J Cardiol. 2008;102:988-993. doi: 10.1016/j. amjcard.2008.05.060.

58. Motoyama S, Masayoshi S, Harigaya H, et al. Computed tomographic angiography characteristics of atherosclerotic plaques subsequently resulting in acute coronary syndrome. J Am Coll Cardiol. 2009;54:49-57. doi: 10.1016/j. jacc.2009.02.068.

59. Kroener E, van Velzen $J$, Boogers $M$, et al. Positive remodeling on coronary computed tomography as a marker for plaque vulnerability on virtual histology intravascular ultrasound. Am J Cardiol. 2011;107:1725-1729. doi: 10.1016/j. amjcard.2011.02.337.

60. Maurovich-Horvat P, Schlett CL, Alkadhi H, et al. The napkin-ring sign indicates advanced atherosclerotic lesions in coronary CT angiography. JACC Cardiovasc Imaging. 2012;5:1243-1252. doi: 10.1016/j.jcmg.2012.03.019.

61. Collin J, Gossl M, Matsuo Y, et al. Osteogenic monocytes within the coronary circulation and their association with plaque vulnerability in patients with early atherosclerosis. Int J Cardiol. 2015;181:57-64. doi: 10.1016/j.ijcard.2014.11.156.

62. Thomsen C, Abdulla J. Characteristics of high-risk coronary plaques identified by computed tomographic angiography and associated prognosis: a systematic review and metaanalysis. Eur Heart J Cardiovasc Imaging. 2016;17:120-129. doi: 10.1093/ ehjci/jev325.

63. Hou ZH, Lu B, Gao Y, et al. Prognostic value of coronary CT angiography and calcium score for major adverse cardiac events in outpatients. JACC Cardiovasc Imaging. 2012;5:990999. doi: 10.1016/j.jcmg.2012.06.006.

64. Mester A, Chitu M, Rat N, et al. CT Determination of Fractional Flow Reserve in Coronary Lesions. Journal of Interdisciplinary Medicine. 2016;1:237-241. doi: 10.1515/jim-2016-0070.

65. Norgaard B, Leipsic J, Gaur S, et al. Diagnostic performance of noninvasive fractional flow reserve derived from coronary computed tomography angiography in suspected coronary artery disease: the NXT trial (analysis of coronary blood flow using CT angiography: next steps). J Am Coll Cardiol. 2014;63:1145-1155. doi: 10.1016/j.jacc.2013.11.043.

66. Orzan M, Stanescu A, Nyulas T, et al. Transluminal Attenuation Gradient for the Noninvasive Assessment of Functional Significance in Coronary Artery Stenoses. Journal of Interdisciplinary Medicine. 2016;1:267-270. doi: 10.1515/ jim-2016-0074.

67. Brown AJ, Teng Z, Evans PC, Gillard JH, Samady H, Bennett MR. Role of biomechanical forces in the natural history of coronary atherosclerosis. Nat Rev Cardiol. 2016;13:210-220. doi: 10.1038/nrcardio.2015.203.
68. Ohayon J, Finet G, Le Floc'h S, et al. Biomechanics of atherosclerotic coronary plaque: site, stability and in vivo elasticity modeling. Ann Biomed Eng. 2014;42:269-279. doi: 10.1007/s10439-013-0888-1.

69. Walsh MT, Cunnane EM, Mulvihill JJ, Akyildiz AC, Gijsen FJ, Holzapfel GA. Uniaxial tensile testing approaches for characterisation of atherosclerotic plaques. J Biomech. 2014;47:793-804. doi: 10.1016/j.jbiomech.2014.01.017.

70. Huang X, Yang C, Zheng J, et al. 3D MRI-based multicomponent thin layer structure only plaque models for atherosclerotic plaques. J Biomech. 2016;49:2726-2733. doi: 10.1016/j.jbiomech.2016.06.002.

71. Zhou A, Chan $\mathrm{H}$, Chughtai A, et al. Automated coronary artery tree extraction in coronary CT angiography using a multiscale enhancement and dynamic balloon tracking (MSCAR-DBT) method. Comput Med Imaging Graph. 2012;36:1-10. doi: 10.1016/j.compmedimag.2011.04.001.

72. Han D, Shim H, Jeon B, et al. Automatic Coronary Artery Segmentation Using Active Search for Branches and Seemingly Disconnected Vessel Segments from Coronary CT Angiography. PLoS One. 2016;11:e0156837. doi: 10.1371/ journal.pone.0156837.

73. Truc PTH, Khan AU, Lee YK, Lee SY, Kim TS. Vessel enhancement filter using directional filter bank. Comput Vis Image Understand. 2009;113:101-112. http://dx.doi. org/10.1016/j.cviu.2008.07.009.

74. Cetin S, Demir A, Yezzi A, Degertekin M, Unal G. Vessel tractography using an intensity based tensor model with branch detection. IEEE Trans Med Imag. 2013;32:348-363. doi: 10.1109/TMI.2012.2227118.

75. Cetin S, Unal G. A higher-order tensor vessel tractography for segmentation of vascular structures. IEEE Trans Med Imag. 2015;34:2172-2185. doi: 10.1109/TMI.2015.2425535.

76. Becker C, Rigamonti R, Lepetit V, Fua P. Supervised feature learning for curvilinear structure segmentation. Med Image Comput Comput Assist Interv. 2013;16:526-533.

77. Su R, Sun CM, Pham TD. Junction detection for linear structures based on Hessian, correlation and shape information. Patt Recogn. 2012;45:3695-3706. http://dx.doi. org/10.1016/j.patcog.2012.04.013.

78. Wang S, Wu JH, Wei MQ, MaX. Robust curve skeleton extraction for vascular structures. Graph Models. 2012;74:109-120. http://dx.doi.org/10.1016/j.gmod.2012.03.008.

79. Wong WCK, So RWK, Chung ACS. Principal curves for lumen center extraction and flow channel width estimation in 3-D arterial networks: Theory, Algorithm, and Validation. IEEE Trans Image Proc. 2012;21:1847-1862. doi: 10.1109/ TIP.2011.2179054.

80. Delibasis KK, Kechriniotis AI, Tsonos C, Assimakis N. Automatic model-based tracing algorithm for vessel segmentation and diameter estimation. Comput Meth Prog Biomed. 2010;100:108-122. doi: 10.1016/j.cmpb.2010.03.00.

81. Wang Y, Liatsis P. Automatic segmentation of coronary arteries in CT imaging in the presence of kissing vessel artifacts. IEEE Trans Inform Technol Biomed. 2012;16:782789. doi: 10.1109/TITB.2012.2192286.

82. Bauer C, PockT, Sorantin E, Bischof H, Beichel R. Segmentation of interwoven 3D tubular tree structures utilizing shape priors and graph cuts. Med Image Anal. 2010;14:172-184. doi: 10.1016/j.media.2009.11.003. 
83. Zhou C, Chan HP, Chughtai A, et al. Automated coronary artery tree extraction in coronary CT angiography using a multiscale enhancement and dynamic balloon tracking (MSCAR-DBT) method. Comput Med Imag Graph. 2012;36:110. doi: 10.1016/j.compmedimag.2011.04.001.

84. Gülsün MA, Funka-Lea G, Zheng YF, Eckert M. CTA coronary labeling through efficient geodesics between trees using anatomy priors. Med Image Comput Comput Assist Interv. 2014;17:521-528.

85. Fabijanska A. Segmentation of pulmonary vascular tree from 3D CT thorax scans. Biocybern Biomed Eng. 2015;35:106-119. http://dx.doi.org/10.1016/j.bbe.2014.07.001.

86. Orkisz M, Hernandez Hoyos M, Pérez Romanello V, et al. Segmentation of the pulmonary vascular trees in 3D CT images using variational region-growing. IRBM. 2014;35:1119. http://dx.doi.org/10.1016/j.irbm.2013.12.001.

87. Rudyanto RD, Kerkstra S, van Rikxoort, et al. Comparing algorithms for automated vessel segmentation in computed tomography scans of the lung: the VESSEL12 study. Med Image Anal. 2014;18:1217-1232. doi: 10.1016/j.media.2014.07.003.

88. Xiao CY, Staring M, Shamonin D, Reiber JHC, Stolk J, Stoel BC. A strain energy filter for 3D vessel enhancement with application to pulmonary CT images. Med Image Anal. 2011;15:112-124. doi: 10.1016/j.media.2010.08.003.

89. Forkert ND, Schmidt-Richberg A, Fiehler J, et al. 3D cerebrovascular segmentation combining fuzzy vessel enhancement and level-sets with anisotropic energy weights. Magn Reson Imaging. 2013;31:262-71. doi: 10.1016/j. mri.2012.07.008.

90. Hassan M, Chaudhry A, Khan A, Kim JY. Carotid artery image segmentation using modified spatial fuzzy c-means and ensemble clustering. Comput Methods Programs Biomed. 2012;108:1261-1276. doi: 10.1016/j.cmpb.2012.08.011.

91. Fathi A, Naghsh-Nilchi AR. Automatic wavelet-based retinal blood vessels segmentation and vessel diameter estimation. Biomed Sign Proc Contr. 2013;8:71-80. http://dx.doi. org/10.1016/j.bspc.2012.05.005.

92. Moghimirad E, Rezatofighi SH, Soltanian-Zadeh. Retinal vessel segmentation using a multi-scale medialness function. Comput Biol Med. 2012;42:50-60. http://dx.doi.org/10.1016/j. compbiomed.2011.10.008.

93. Cimen S, Hoogendoorn C, Morris PD, Gunn J, Frangi AF. Reconstruction of coronary trees from 3DRA using a 3D+t statistical cardiac prior. Med Image Comput Comput Assist Interv. 2014;17:619-626.

94. Cimen S, Gooya A, Ravikumar N, Taylor ZA, Frangi AF. Reconstruction of coronary artery centrelines from X-ray angiography using a mixture of student's t-distributions. Lecture Notes in Computer Science (MICCAI). 2016;9902:291299. doi: 10.1007/978-3-319-46726-9_34.

95. Hu Y, Jung M, Oukili A, et al. Sparse reconstruction from a limited projection number of the coronary artery tree in $\mathrm{X}$-ray rotational imaging. IEEE Int Symp Biomed Imag (ISBI). 2012; pp. 804-807. doi: 10.1109/ISBI.2012.6235670.

96. Fallavollita P, Cheriet F. Optimal 3D reconstruction of coronary arteries for 3D clinical assessment. Comput Med Imaging Graph. 2008;32:476-487. doi: 10.1016/j. compmedimag.2008.05.001.

97. Gülsün MA, Funka-Lea G, Sharma P, Rapaka S, Zheng YF. Coronary centerline extraction via optimal flow paths and
CNN path pruning. Lecture Notes in Computer Science (MICCAI). 2016;9902:317-325. doi: 10.1007/978-3-31946726-9_37.

98. Kitamura Y, Li YZ, Ito W. Automatic coronary extraction by supervised detection and shape matching. IEEE Int Symp Biomed Imag (ISBI). 2012;234-237. doi: 10.1109/ ISBI.2012.6235527.

99. Dufour A, Tankyevych O, Naegel B, et al. Filtering and segmentation of 3D angiographic data: Advances based on mathematical morphology. Med Image Anal. 2013;17:147164. http://dx.doi.org/10.1016/j.media.2012.08.004.

100. Krissian K, Carreira JM, Esclarin J, Maynar M. Semi-automatic segmentation and detection of aorta dissection wall in MDCT angiography. Med Image Anal. 2014;18:83-102. doi: 10.1016/j. media.2013.09.004.

101. Shang YF, Deklerck R, Nyssen E, et al. Vascular active contour for vessel tree segmentation. IEEE Trans Biomed Eng. 2011;58:1023-1032. doi: 10.1109/TBME.2010.2097596.

102. Shin SY, Lee S, Noh KJ, Yun ID, Lee KM. Extraction of coronary vessels in fluoroscopic $\mathrm{X}$-ray sequences using vessel correspondence optimization. Lecture Notes in Computer Science (MICCAI). 2016;9902:308-316. doi: 10.1007/978-3319-46726-9_36.

103. Liu L, Shi WZ, Rueckert D, Hu MX, Ourselin S, Zhuang XH. Model-guided directional minimal path for fully automatic extraction of coronary centerlines from cardiac CTA. Med Image Comput Comput Assist Interv. 2013;16:542-549.

104. Liu L, Shi WZ, Rueckert D, Hu MX, Ourselin S, Zhuang XH. Coronary centerline extraction based on ostium detection and model-guided directional minimal path. IEEE Int Symp Biomed Imag (ISBI). 2014;133-136. doi: 10.1109/ ISBI.2014.6867827.

105. Sun SY, Wang P, Sun SH, Chen T. Model-guided extraction of coronary vessel structures in 2D X-ray angiograms. Med Image Comput Comput Assist Interv. 2014;17:594-602.

106. Medrano-Garcia P, Ormiston J, Webster M, et al. Construction of a coronary artery atlas from CT angiography. Med Image Comput Comput Assist Interv. 2014;17:513-520.

107. Zheng YF, Tek H, Funka-Lea G. Robust and accurate coronary artery centerline extraction in CTA by combining modeldriven and data-driven approaches. Med Image Comput Comput Assist Interv. 2013;16:74-81.

108. Perona P, Malik J. Scale space and edge detection using anisotropic diffusion. IEEE Trans Patt Anal Mach Intell. 1990;12:629-639.

109. Frangi AF, Niessen WJ, Vincken KL, Viergever MA. Multiscale vessel enhancement filtering. Lecture Notes in Computer Science (MICCAI). 1998;1496:130-137.

110. Han DJ, Doan NT, Shim H, et al. A fast seed detection using local geometrical feature for automatic tracking of coronary arteries in CTA. Comput Methods Programs Biomed. 2014;117:179-188. doi: 10.1016/j.cmpb.2014.07.005.

111. Benyó B. Identification of dental root canals and their medial line from micro-CT and cone-beam CT records. BioMed Eng Online 2012;11:81. doi: 10.1186/1475-925X-11-81.

112. Au OKC, Tai CL, Chu HK, Cohen-Or D, Lee TY. Skeleton extraction by mesh contraction. ACM Trans Graph. 2008;27:110.

113. Hoffmann U, Bamberg F, Chae CU, et al. Coronary computed tomography angiography for early triage of patients with acute chest pain: the ROMICAT (Rule Out Myocardial 
Infarction using Computer Assisted Tomography) trial. J Am Coll Cardiol. 2009;53:1642-1650. doi: 10.1016/j. jacc.2009.01.052.

114. Hoffman U, Truong Q Schoenfield D, et al. Coronary CT angiography versus Standard Evaluation in Acute Chest Pain. N Engl J Med. 2012;367:299-308. doi: 10.1056/NEJMoa1201161.

115. Kolansky DM. Acute coronary syndromes: morbidity, mortality, and pharmacoeconomic burden. Am J Manag Care. 2009;15:36-41.

116. Hagan PG, Nienaber CA, Isselbacher EM, et al. The International Registry of Acute Aortic Dissection (IRAD): new insights into an old disease. JAMA. 2000;283:897-903.
117. Eagle KA, Lim MJ, Dabbous OH, et al. A validated prediction model for all forms of acute coronary syndrome: estimating the risk of 6-month postdischarge death in an international registry. JAMA. 2004;9;291:2727-2733. doi:10.1001/ jama.291.22.2727.

118. Kristensen TS, Kofoed KF, Kühl JT, Nielsen WB, Nielsen MB, Kelbæk HJ. Prognostic implications of non-obstructive coronary plaques in patients with non-ST-segment elevation myocardial infarction: a multidetector computed tomography study. J Am Coll Cardiol. 2011;58:502-509. doi: 10.1016/j. jacc.2011.01.058. 